\title{
COMPARAÇÃO DO PERFIL DE ANTICORPOS ANTI- IMUNOGLOBULINA G EM MURINOS IMUNIZADOS COM IgG HUMANA ASSOCIADA A DIFERENTES ADJUVANTES
}

\author{
Comparing the profile of anti-immunoglobulin $G$ in murine immunized with \\ human IgG associated with different adjuvants \\ Marcus Vinicius O. Nunes ${ }^{1,2^{\star}}$, Camila P. Câmara ${ }^{1,2}$, \\ Adriana de Moraes Costa Crespo ${ }^{1,3}$, Mara Carvalhaes ${ }^{3}$, \\ Cristina Rodrigues de Oliveira ${ }^{1,4}$ e Lucimeire Antonelli da Silveira ${ }^{1,3}$
}

${ }^{1}$ Centro de Produção de Anticorpos do Centro-Oeste (CEPRACO), Instituto de Patologia Tropical e Saúde Pública (IPTSP), Universidade Federal de Goiás.Praça Universitária s/n. 74605-220. Goiânia-GO, Brasil.

${ }^{2}$ Acadêmicos de Farmácia da FF/UFG;

${ }^{3}$ Prof ${ }^{a}$ de Imunologia do IPTSP/UFG;

${ }^{4}$ Biomédica e técnico-administrativo IPTSP/UFG.

*Autor para correspondência e-mail: marcusnune@gmail.com

Recebido em 10/10/2008 - Aceito em 15/12/2008

RESUMO: Adjuvantes são substâncias associadas aos antígenos que aumentam ou modificam a resposta imune. Este trabalho constitui uma comparação do perfil de anticorpos em grupos de murinos imunizados com lgG humana associada ou não a adjuvantes, através da técnica de Enzyme Linked Immunosorbent Assay (ELISA) no $28^{\circ}$ e $40^{\circ}$ dia após esquema de imunização previamente delineado. Os adjuvantes avaliados nesse estudo foram o hidróxido de alumínio e o adjuvante de Freund. Os resultados demonstraram que no $28^{\circ}$ dia os animais imunizados com adjuvantes exibiram valores de absorbância mais altos em comparação com animais imunizados sem adjuvantes e os murinos imunizados com hidróxido de alumínio e adjuvante de Freund apresentaram valores de densidade ótica semelhantes. Em contradição, no $40^{\circ}$ dia nos três grupos de camundongos estudados, o perfil de anticorpos anti - Ig G humana foram análogos.

PALAVRAS-CHAVE: Adjuvantes imunológicos, Imunização, Anti - IgG humana.

ABSTRACT: Adjuvants are substances associated with antigens that increase or modify the imune response. This work/study is a comparison of the profile of murine antibodies in groups immunized with human IgG associated or not with adjuvants, using the Enzyme Linked Immunosorbent Assay (ELISA) technique in the $28^{\text {th }}$ and $40^{\text {th }}$ days after immunization. The adjuvants evaluated in this work/study were the aluminium hydroxide and Freund's adjuvant. The results showed that in $28^{\text {th }}$ day the mice immunizad with adjuvants exhibited higher values of absorbance compared with the animals immunized without adjuvants. However, it was found that the murine immunized with aluminium hydroxide and Freund's adjuvant showed similar values of optical density. In contradiction, in the $40^{\text {th }}$ day the groups of mice examined showed analogues profiles of anti-human IgG.

KEY WORDS: Immunological Adjuvants, Immunization, Anti-human IgG.

\section{INTRODUÇÃo}

A indução da resposta imune é conhecida como imunização. As imunizações experimentais são rotineiramente provocadas pela inoculação de antígeno no animal ou no homem (JANEWAY et al., 2002). Antígenos geralmente têm massa molecular de pelo menos 10000 Daltons. O grau de imunogenicidade geralmente aumenta com a massa molecular. A imunogenicidade é a capacidade do antígeno de gerar resposta imunológica, e antigenicidade é a capacidade da substância reagir com anticorpos. Um antígeno completo deve possuir ambas características (ALOISI, 1979). As imunoglobulinas heterológas possuem uma excelente imunogenicidade. Os anticorpos da classe lgG são compostos por quatro cadeias polipeptídicas, sendo que duas 
apresentam peso molecular de aproximadamente 25000 Daltons (cadeias leves) e as outras duas com peso molecular de 50000 Daltons (cadeias pesadas), sendo portanto ótimos imunógenos (EDELMAN, 1959).

Adjuvantes são substâncias associadas aos antígenos que aumentam ou modificam a resposta imune. Deste modo, a produção de anticorpos ou as reações imunes mediadas por células são mais vigorosas do que aquelas em que o antígeno é injetado sem adjuvantes. Entretanto, a resposta pode ser modificada qualitativamente, podendo estimular a produção de diferentes tipos de imunoglobulinas (HERBERT E WILKINSON, 1977). Os adjuvantes possuem efeito de depósito caracterizado pela lenta liberação do antígeno, retardando sua absorção e destruição, e consequentemente prolongando o tempo do estímulo imunológico. Além disso, potencializam a apresentação de antígenos pelas células apresentadoras de antígeno (APCs) e induzem a maturação de células dendríticas através da ativação de células T (PLOTKIN e ORENSTEIN, 2004).

De acordo com suas características físicas, essas substâncias são classificadas em adjuvantes surfactantes, adjuvantes em forma de vesículas e os solúveis em água. Os primeiros podem ser inorgânicos (hidróxido de alumínio); orgânicos naturais (LPS); e orgânicos sintéticos (lipopeptídeos). Os adjuvantes em forma de vesícula se classificam em: emulsões (adjuvante de Freund); lipossomas; complexos imunoestimulantes (ISCOM's); e sistemas particulados (nanopartículas, proteossomas). Por último, temos como exemplos de adjuvantes solúveis em água as citocinas, a cólera toxina e o muramil dipeptídeo (WOODARD, 1990).

Segundo A Compendium of Vaccine Adjuvants and Excipients do National Institute of Allergy and Infectious Diseases (NIAID), o adjuvante completo de Freund (CFA) é uma mistura viscosa sem cor constituída de $85 \%$ de óleo mineral, $15 \%$ de emulsificante com $500 \mu \mathrm{g}$ de Mycobacterium tuberculosis inativada por mililitro de emulsão. Já o adjuvante incompleto de Freund (IFA) não possui o constituinte bacteriano. Segundo esse mesmo compêndio o Alhydrogel ou gel de hidróxido de alumínio tem uma estrutura cristalina de oxihidróxido de alumínio $(\mathrm{AIOOH})$, caracterizado pela formação de um precipitado branco e gelatinoso em suspensão aquosa. Às vezes o termo alum é usado de forma genérica, mas incorreta para o hidróxido de alumínio como para o fosfato de alumínio, mas de acordo com The Merck Index é correto o emprego quimicamente para o sulfato de potássio e alumínio.

Freund (1956) sugeriu que existem três categorias de mecanismos de ação para o CFA que são: prolongar a presença do antígeno no local da injeção; e promover o transporte mais eficaz dos antígenos para o sistema linfático e para os pulmões, onde o adjuvante promoveria o acúmulo de células inflamatórias; e outros mecanismos ainda não identificados . O adjuvante incompleto de Freund, além de seu efeito de depósito, tem a capacidade de induzir processos inflamatórios, aumentando o infiltrado de células inflamatórias e/ou a capacidade de estimular as funções das células apresentadoras de antígeno (APC), potencializando a resposta das células T específicas (GUPTA et al., 1993).

O hidróxido de alumínio forma agregados porosos que irão absorver o antígeno em seus espaços intersticiais promovendo imunopotenciação, justificando seu efeito de depósito (MĖNDEZ et al., 2007). A imunização com compostos a base de alumínio pode formar depósitos dentro dos macrófagos do tecido muscular produzindo "miofascite macrofágica" que pode estar ligada a sintomas como dor e fadiga, em associação com outras condições, incluindo as de natureza autoimune (GHERARDI et al., 2001).

O conhecimento sobre a resposta imune natural pode ser utilizado para obter novos adjuvantes com design específico para um tipo particular de imunopotenciação. A natureza dos adjuvantes pode influenciar o tipo de resposta imune com ativação de subtipos de células $T$, Th1 ou Th2, induzindo uma resposta predominantemente celular ou humoral com produção de determinados isótipos de anticorpos (PAUL, 2003). Além disso, os adjuvantes são amplamente utilizados na imunização de animais destinados à produção de anticorpos monoclonais, e principalmente na imunização preventiva de seres humanos frente às doenças infecciosas.

No presente trabalho pretendemos comparar o perfil de anticorpos anti-imunoglobulina $G$ em camundongos $B A L B / C$ imunizados com imunoglobulina $G$ humana associada aos adjuvantes de Freund e ao hidróxido de alumínio.

\section{MATERIAL E MÉTODOS}

\section{Animais}

Foram utilizados camundongos da linhagem $B A L B / c$, fêmeas, de 2 meses de idade. Os animais foram fornecidos pelo Biotério do Instituto de Patologia Tropical e Saúde Pública (IPTSP) da Universidade Federal de Goiás (UFG), e mantidos no Centro de Produção de Anticorpos Monoclonais do Centro Oeste (CEPRACO), onde foram realizados os procedimentos experimentais.

\section{Antígenos e adjuvantes}

O antígeno empregado na imunização foi à imunoglobulina G total humana purificada (Sigma USA). Os adjuvantes avaliados neste experimento foram o adjuvante completo e incompleto de Freund (Sigma, USA) e o hidróxido de alumínio (Laboratório Teuto Brasileiro S/A, Brasil). 
Os camundongos foram separados em três grupos. O grupo 1, constituído por três camundongos, foi imunizado somente com antígeno. No grupo 2, composto por cinco camundongos, foi injetado antígeno associado ao adjuvante de Freund. Já o grupo 3, também formado por cinco camundongos, recebeu a associação de IgG total humana e gel de hidróxido de alumínio. A via de imunização foi à subcutânea, na qual se injetou $0,1 \mathrm{ml}$ de inóculo por animal utilizando-se $10 \mu \mathrm{g}$ de IgG diluída em tampão fosfato salino (PBS) com ou sem adjuvante, seguindo o cronograma de imunização da Tabela 1. O volume de adjuvante completo de Freund utilizado por camundongo estava em conformidade com o estabelecido pelo Guidelines for the Research Use of Adjuvants da Office of Animal Care and Use Staff (OACU), que preconiza o uso de volume menor ou igual 0,1 ml por essa via de imunização. $O$ adjuvante de Freund com a solução antigênica foi homogeneizado em vórtex até adquirir uma coloração branca homogênea, conforme método de Flies e Chen (2003) modificado.

Tabela 1 - Cronograma de imunização dos três grupos de animais avaliados demonstrando as quantidades de antígeno e adjuvantes injetados por camundongo.

\begin{tabular}{cccccc}
\hline Dia & Grupo & $\begin{array}{c}\mathrm{IgG} \\
(\mu \mathrm{g})\end{array}$ & $\begin{array}{c}\mathrm{CFA}^{1} \\
(\mu \mathrm{l})\end{array}$ & $\begin{array}{c}\mathrm{IFA}^{2} \\
(\mu \mathrm{l})\end{array}$ & $\begin{array}{c}\text { Gel de hidróxido de } \\
\text { alumínio }(\mu \mathrm{g})\end{array}$ \\
\hline 0 & 1 & 10 & - & - & - \\
& 2 & 10 & 50 & - & - \\
& 3 & 10 & - & - & 180 \\
\hline 7 & 1 & 10 & - & - & - \\
& 2 & 10 & - & 50 & - \\
& 3 & 10 & - & - & 180 \\
\hline 21 & 1 & 10 & - & - & - \\
& 2 & 10 & - & 50 & - \\
& 3 & 10 & - & - & 180 \\
\hline
\end{tabular}

Coleta de sangue

\begin{tabular}{cccccc}
\hline 35 & 1 & 10 & - & - & - \\
& 2 & 10 & - & 50 & - \\
& 3 & 10 & - & - & 180 \\
\hline
\end{tabular}

40

Coleta de sangue

$\overline{\text { CFA }}^{1}$ - Adjuvante completo de Freund. IFA ${ }^{2}$ - Adjuvante incompleto de Freund

\section{Preparação das amostras}

O sangue dos animais foi coletado e centrifugado para separação do soro, que foi armazenado em freezer a $-20{ }^{\circ} \mathrm{C}$ para posterior realização de ensaio imunoenzimático.

\section{Avaliação da resposta sorológica por ELISA}

Às imunizações foram avaliadas através do ensaio de Enzyme Linked Immunosorbent Assay (ELISA) indireto no $28^{\circ}$ e $40^{\circ}$ dia após esquema de imunização empregado. Placas de 96 cavidades (Corning Incorporated Costar, USA) foram sensibilizadas com $50 \mu \mathrm{l}$ de solução de $\mathrm{lgG}$ humana na concentração $10 \mu \mathrm{g} / \mathrm{ml}$ e incubadas overnight, a $4^{\circ} \mathrm{C}$. Terminada a sensibilização, lavou-se com PBS e realizou-se o bloqueio dos sítios não sensibilizados da placa com PBS-leite $5 \%$. Incubou-se durante 2 horas a $37^{\circ} \mathrm{C}$ em câmara úmida. Em seguida, as placas foram incubadas por $1 \mathrm{~h}$ à $37^{\circ} \mathrm{C}$ com diluição seriada do soro dos animais, controle positivo (pool de soros imunes) e controle negativo (pool de soros não imunes). Posteriormente, as placas foram lavadas e incubadas com conjugado composto por anticorpo de coelho anti-IgG de camundongo marcado com peroxidase (Rabbit antiMouse IgG $[H+L]$ HPR Conjugate, Zymax, USA) na diluição $1: 15000$ e novamente incubadas por $1 \mathrm{~h}$ à $37^{\circ} \mathrm{C}$. A seguir, as placas foram novamente lavadas com PBS e incubadas com peróxido de hidrogênio (Abbott) e 
tetrametilbenzidina (TMB - Abbott) por 30 minutos. A reação foi bloqueada com $\mathrm{HCl} 2 \mathrm{~N}$ e a leitura foi efetuada em aparelho de ELISA no comprimento de onda de $450 \mathrm{~nm}$.

\section{Análise estatística}

As análises foram realizadas utilizando-se o programa Biostat ${ }^{\circledR}$ 2007. As médias foram comparadas através do método de Scheffé. Cada grupo foi estudado estabelecendo-se o nível de significância $\alpha=5 \%$.

\section{RESULTADOS E DISCUSSÃO}

O gráfico 1 demonstra que o Grupo 1 cujos camundongos foram imunizados apenas com a IgG humana, apresentou valores de absorbância mais baixos em comparação com os Grupos 2 e 3, imunizados com o antígeno associado, respectivamente, com adjuvante de Freund e hidróxido de alumínio, que apresentaram resultados semelhantes entre si (Gráfico 1).

Gráfico 1 - Titulação dos soros dos três grupos de camundongos avaliados no $28^{\circ}$ dia após esquema de imunização empregado.

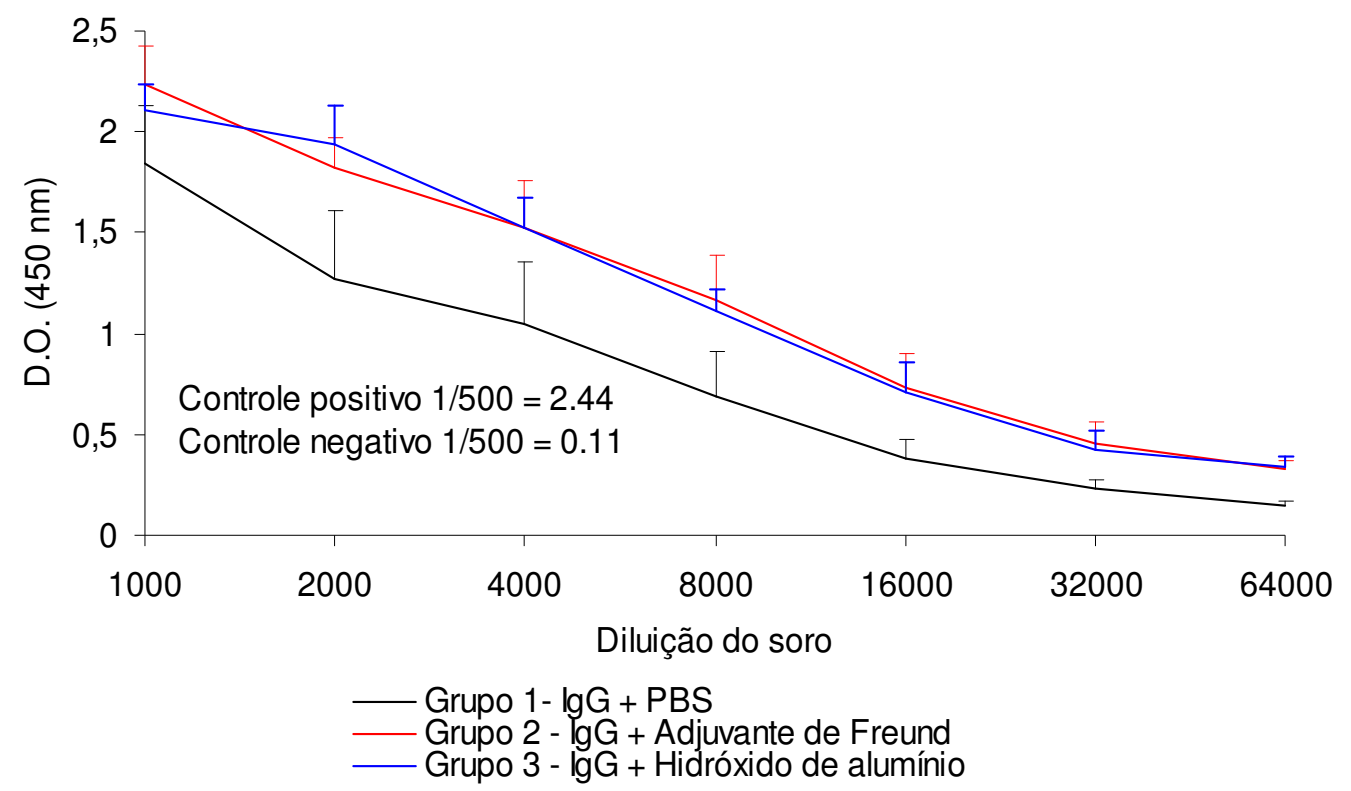

Os valores individuais da absorbância (450 nm) e as médias na diluição de 1:64000 do soro de cada grupo (Tabela 2) submetidas ao método de Scheffé mostrou que as médias dos grupos 2 e 3 não possuem diferenças estatisticamente significativas, mas essa pode ser observada quando na análise conjunta entre os grupos 1 e 2 , e 1 e 3, como pode ser visto na Tabela 3. Os pontos referentes as outras diluições foram submetidas a essa mesma análise, mas não demonstraram diferenças estatisticamente significantes (dados não apresentados).

Tabela 2 - Valores individuais e médias de absorbância na diluição 1:64000 do soro em camundongos Balb/c no $28^{\circ}$ dia após esquema de imunização empregado, segundo grupos de estudo.

\begin{tabular}{ccc}
\hline Grupo 1 & Grupo 2 & Grupo 3 \\
\hline 0,15 & 0,39 & 0,28 \\
0,17 & 0,35 & 0,30 \\
0,12 & 0,31 & 0,42 \\
& 0,36 & 0,31 \\
& 0,24 & 0,37 \\
\hline $\mathrm{n}_{1}=3$ & $\mathrm{n}_{2}=5$ & $\mathrm{n}_{3}=5$ \\
$\mathrm{M}_{1}=0,15$ & $\mathrm{M}_{2}=0,33$ & $\mathrm{M}_{3}=0,34$ \\
\hline
\end{tabular}

Tabela 3 - Comparação entre pares de média dos grupos 1, 2 e 3 pelo método de Scheffé 28o dia após esquema de imunização empregado.

\begin{tabular}{ccccc}
\hline Grupos & Diferença & Teste Estatístico & Valor crítico $(5 \%)$ & Hipótese \\
\hline $1 \times 2$ & -0.18 & 4.75 & 2.79 & aceita
\end{tabular}



$1 \times 3$
$-0.19$
4.9
2.79
aceita
$2 \times 3$
$-0.01$
0.18
2.79
rejeita

A avaliação dos títulos de anticorpos produzidos no $40^{\circ}$ dia após o esquema de imunização proposto, revelou entre os grupos analisados, valores de absorbância semelhantes (Gráfico 2).

Gráfico 2 - Titulação dos soros dos três grupos de camundongos avaliados no $40^{\circ}$ dia após esquema de

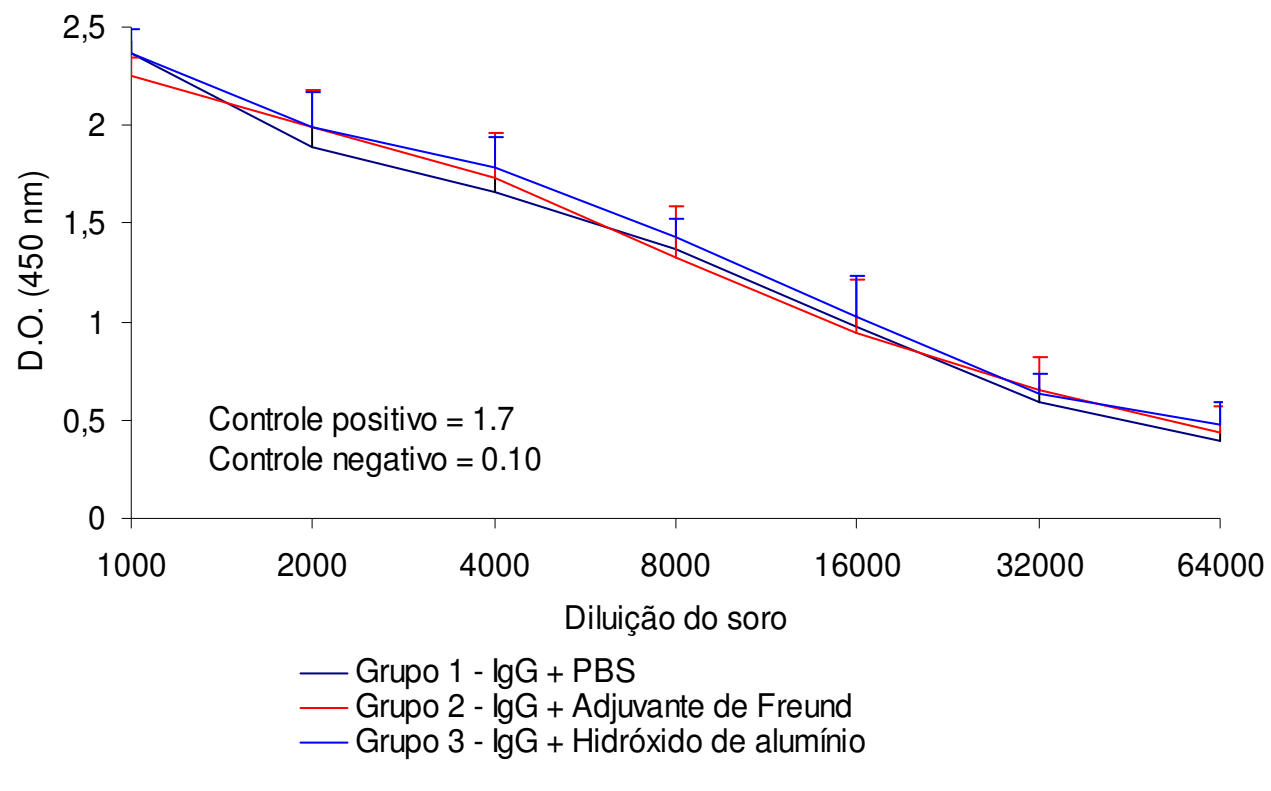

imunização empregado.

Submetidos a análise estatística pelo método de Scheffé, os valores de densidade óptica apresentados no 40ํ dia após imunização, na diluição de soro 1:64000 (Tabela 5), demonstraram que as diferenças entre as médias dos grupos não são estatisticamente significativas (Tabela 6).

Tabela 5 - Valores individuais e médias de absorbância na diluição 1:64000 do soro em camundongos Balb/c 40 dia após esquema de imunização empregado segundo grupo de estudo.

\begin{tabular}{ccc}
\hline Grupo 1 & Grupo 2 & Grupo 3 \\
\hline 0,47 & 0,31 & 0,66 \\
0,40 & 0,66 & 0,49 \\
0,30 & 0,55 & 0,31 \\
& 0,36 & 0,37 \\
& 0,32 & 0,55 \\
\hline $\mathrm{n}_{1}=3$ & $\mathrm{n}_{2}=5$ & $\mathrm{n}_{3}=5$ \\
$\mathrm{M}_{1}=0,39$ & $\mathrm{M}_{2}=0,44$ & $\mathrm{M}_{3}=0,48$ \\
\hline
\end{tabular}

Tabela 6 - Comparação entre pares de média dos grupos 1, 2 e 3 pelo método de Scheffé $40^{\circ}$ dia após esquema de imunização empregado.

\begin{tabular}{ccccc}
\hline Grupos & Diferença & Teste Estatístico & Valor crítico $(5 \%)$ & Hipótese \\
\hline $1 \times 2$ & $-0,05$ & 0,47 & 2,79 & rejeita \\
$1 \times 3$ & $-0,08$ & 0,82 & 2,79 & rejeita \\
$2 \times 3$ & $-0,04$ & 0,40 & 2,79 & rejeita \\
\hline
\end{tabular}

Através da análise dos dados obtidos podemos concluir que no $28^{\circ}$ dia, após imunização, houve aumento da resposta sorológica nos grupos 2 e 3, em comparação com o grupo 1 na diluição de soro de 1:64000. Esse resultado demonstra a importância dos adjuvantes na estimulação da imunidade natural, principalmente no primeiro contato com o antígeno. Diferentemente de outros trabalhos (LEAL et al., 2002; THOMSON et al., 1983), em que o adjuvante completo de Freund comparado ao hidróxido de alumínio, apresentou uma melhor indução da 
resposta imune, o presente trabalho demonstra que os níveis de anticorpos produzidos nos grupos estudados com diferentes adjuvantes, são semelhantes. As outras diluições não apresentaram diferenças estatisticamente significativas, possivelmente dado ao fato dos valores de densidade óptica terem variado muito dentro de um mesmo grupo.

Entretanto no 40ํ dia, após a imunização, constatou-se que os grupos apresentaram níveis semelhantes de anti-lgG humana no soro. Esses resultados nos mostram que após sucessivas imunizações, o sistema imune do animal desenvolve memória imunológica, e conseqüentemente, uma resposta mais específica e rápida, dispensando nas imunizações secundárias o uso de adjuvantes.

Thomson et al. (1983) demonstraram os efeitos de diferentes adjuvantes em camundongos $B A L B / c$ infectados com o vírus Herpes simplex 1 (HSV-1) inteiro ou com antígeno do envelope viral (EAG). A combinação da vacina EAG ou do vírus inteiro com adjuvante completo de Freund produziu completa proteção ás lesões primárias. Entretanto, a reatogenicidade desse adjuvante impossibilita seu uso clínico em seres humanos, pois já foi associado à hiperplasia linfóide, à formação de granuloma, susceptibilidade aumentada ao choque endotóxico e sensibilização a tuberculina, demonstrando-se a necessidade de encontrar outros adjuvantes também eficazes, mas livres de efeitos adversos graves. O uso de hidróxido de alumínio não demonstrou a eficácia do adjuvante completo de Freund em relação às vacinas HSV-1, mas ofereceu uma proteção significativa. Em outro trabalho, que avaliou a resposta sorológica de coelhos imunizados com antígenos de Pythium insidiosum, verificou-se que o adjuvante de Freund induziu maiores níveis de anticorpos IgG, comparado aos adjuvantes: óleo mineral e hidróxido de alumínio.

Em contraste, Ding et al. (2000) verificaram que camundongos imunizados com vacina multi-epítopo em alum, poderia induzir altos níveis de anticorpos de especificidade predefinida contra HIV-1 em comparação com o adjuvante de Freund. Experimentos que avaliaram a relação entre macrófagos e adjuvantes à base de alumínio in vitro mostraram a indução da expressão de CD83, um aumento da expressão de CD86 e a indução da capacidade de macrófagos em potencializar a proliferação de linfócitos T autólogos de memória imunológica, sugerindo uma associação entre modificações fenotípicas e funcionais induzidas por esses adjuvantes (RIMANIOL et al., 2007).

A utilização de diferentes adjuvantes pode influenciar o tipo de resposta de células T CD4+, assim como a produção de subclasses de anticorpos. Ebhardt et al. (2002) demonstraram que camundongos BALB/c de 16 a 22 meses de idade imunizados com antígeno eggwhite lysozyme (HEL) emulsionados com CFA, desenvolveram resposta vigorosa de células T helper 1 (Th1), caracterizada pela produção de IFN- $\square$ e IL-12, não havendo produção significativa de IL-5. Resposta semelhante foi observada em camundongos adultos jovens (6-8 semanas). Consistente com a indução tipo Th1, detectou-se anticorpos específicos para HEL da subclasse lgG2a em ambos os grupos. Em contraste, os camundongos mais velhos imunizados com HEL emulsionado com IFA ou alum demonstraram forte resposta T helper 2 (Th2) com produção de IL-5, semelhante ao observado em adultos jovens. Entretanto, as duas faixas de idade analisadas revelaram a produção de anticorpo especifico para $H E L$ da subclasse lgG1, mas não houve produção significativa de lgG2a, consistente com a resposta Th2. Demonstrando que o tipo de resposta independe da idade do camundongo.

Goto et al. (2007) realizaram a identificação e caracterização da esterol 24-c metiltransferase (SMT) de Leishmania, e imunizaram camundongos com esse antígeno associado ao adjuvante monofosforil lipídeo A $\left(\mathrm{MPL}^{\circledR}-\mathrm{SE}\right)$. Os animais desenvolveram respostas imunes antígeno específica do tipo Th1, caracterizada por grande produção de IFN-y.

Podemos inferir, portanto que, o uso apropriado de adjuvantes pode significar a redução da quantidade de antígeno por dose, criando a capacidade de produzir grandes quantidades de vacinas. Além disso, os adjuvantes também podem auxiliar no desenvolvimento de novos sistemas de liberação e vias de administração de antígeno, aumentando a eficiência dos esquemas de imunização empregados e inclusive direcionar a resposta imune, visando interferir em suas propriedades de especialização, de forma a torná-la mais apropriada a agentes patogênicos do tipo extracelulares ou intracelulares, para o qual se pretende induzir uma imunidade mais duradoura.

\section{CONCLUSÃO}

Os resultados demonstraram que, após esquema de imunização utilizado até o $28^{\circ}$ dia, os adjuvantes de Freund e hidróxido de alumínio quando associados ao antígeno, induziram resposta imune humoral com produção de anticorpos anti - IgG humana, semelhantes nesses grupos, diferindo do perfil observado no grupo imunizado somente com o antígeno. Entretanto, após efetuado o esquema de imunização proposto, nos três grupos estudados, o perfil de anticorpos foram semelhantes entre si.

\section{REFERÊNCIAS BIBLIOGRÁFICAS}

ALOISI, R.M. Principles of Immunodiagnostics. The C.V. Mosby Company. St. Louis, 1979. p. 47 - 52.

DING, J. et al. Candidate multi-epitope vaccines in aluminium adjuvant induce high levels of antibodies with predefined multi-epitope specificity against HIV-1. Immunology and Medical Microbiology 29: 123-127, 2000. 
EBHARDT, M.B. et al. Immunological adjuvants efficiently induce antigen-specific T cell responses in old mice: implications for vaccine adjuvant development in aged individuals. Cellular Immunology 215: 87-97, 2002.

EDELMAN, G.M. Dissociation of gamma globulin. J. AM. Chem. Soc. 81: 3155, 1959.

FLIES, D.B.; CHEN, L. A simple and rapid vortex method for preparing antigen/adjuvant emulsions for immunization. Journal of Immunological Methods 276: 239-242, 2003.

FREUND, J. The mode of action of immunologic adjuvants. Adv. Tuberc. Res. 7: 130-148, 1956.

GHERARDI, R.K. et al. Macrophagic myofasciitis lesions assess long-term persistence of vaccine-derived aluminium hydroxide in muscle. Brain 124: 1821-31, 2001.

GOTO, Y. et al. Protective immunization against visceral leishmaniasis using Leishmania sterol 24-cmethyltransferase formulated in adjuvant. Vaccine 25: 7450-7458, 2007.

GUPTA, R.K. et al. Adjuvants: a balance between toxicity and adjuvanticity. Vaccine 11: 293-306, 1993.

HERBERT, W.J., WILKINSON, P.C. A dictionary of Immunology. $2^{\text {nd }}$ ed. Blackwell Scientific Publications. Oxford, 1977. p. $3-4$.

JANEWAY, C.A. et al. Imunobiologia: o sistema imune na saúde e na doença. 5a ed. Artmed .Porto Alegre, 2002. p. $639-644$.

LEAL, A.T. et al. Resposta sorológica de coelhos imunizados com antígenos de Pythium insidiosum associados a diferentes adjuvantes. Ciência Rural 32: 1027 - 1032, 2002.

MENDEZ, I.Z.R. et al. Potentiation of the immune response to non-adsorbed antigens by aluminum-containing adjuvants. Vaccine 25(5): 825-33, 2007.

MERCK. The Merck Index. 12th ed. Merck and Co., 1996.p. 63.

NATIONAL INSTITUTE OF ALLERGY AND INFECTIOUS DISEASES, NATIONAL INSTITUTES OF HEALTH. $A$ Compendium of Vaccine Adjuvants and Excipients. Disponível <http://www.niaid.nih.gov/hivvaccines/pdf/compendium.pdf>. Acesso em: 03 de novembro de 2007.

OFFICE OF ANIMAL CARE AND USE STAFF, NATIONAL INSTITUTES OF HEALTH. Guidelines for the Research Use of Adjuvants. Disponível em: <http://oacu.od.nih.gov/ARAC/freunds.pdf>. Acesso em: 03 de novembro de 2007.

PAUL, W.E. Fundamental Immunology. 5 ${ }^{\mathrm{a}}$ ed. Lippincott Williams \& Wilkins. Philadelphia, 2003. p. 1337 - 1342.

PLOTKIN, S.A., ORENSTEIN, W.A. Vaccines. $4^{\text {th }}$ ed. Saunders. Philadelphia, 2004. p.69-79.

RIMANIOL, A.C. et al. In vitro interactions between macrophages and aluminum-containing adjuvants. Vaccine 25: 6784-6792, 2007.

THOMSON, T.A. et al. Comparison of Effects of Adjuvants on Efficacy of Virion Envelope Herpes Simplex Virus Vacine Against Labial Infection of Balb/c Mice. Infection and Immunity 42: 556-562, 1983.

WOODARD, L.F. Surface chemistry and classification of vaccine adjuvants and vehicles. Advances in biotechnological processes 13: 281-306, 1990. 